\title{
Impact of Lymphadenectomy on Short- and Long- term Complications in Patients With Endometrial Cancer
}

\section{Louisa Proppe ( $\square$ Louisa.Proppe@uksh.de)}

University Hospital Schleswig Holstein Department of Hygiene: Universitatsklinikum Schleswig Holstein Medizinaluntersuchungsamt und Hygiene Kiel https://orcid.org/0000-0003-1989-2267

\section{Ibrahim Alkatout}

University Hospital Schleswig-Holstein

\section{Ricarda Koch}

University Hospital Schleswig Holstein Department of Hygiene: Universitatsklinikum Schleswig Holstein Medizinaluntersuchungsamt und Hygiene Kiel

\section{Sascha Baum}

University Hospital Schleswig Holstein Department of Hygiene: Universitatsklinikum Schleswig Holstein Medizinaluntersuchungsamt und Hygiene Kiel

\section{Christos Kotanidis}

Vivantes Humboldt, Berlin

\section{Rody Achim}

University Hospital Schleswig Holstein Department of Hygiene: Universitatsklinikum Schleswig Holstein Medizinaluntersuchungsamt und Hygiene Kiel

\section{Lars C. Hanker}

University Hospital Schleswig Holstein Department of Hygiene: Universitatsklinikum Schleswig Holstein Medizinaluntersuchungsamt und Hygiene Kiel

\section{Georgios Gitas}

University Hospital Schleswig Holstein Department of Hygiene: Universitatsklinikum Schleswig Holstein Medizinaluntersuchungsamt und Hygiene Kiel https://orcid.org/0000-0002-9242-8041

\section{Research Article}

Keywords: Endometrial cancer, lymphatic complications, lymphadenectomy, surgical complications

Posted Date: June 4th, 2021

DOI: https://doi.org/10.21203/rs.3.rs-430130/v1 
License: (c) (i) This work is licensed under a Creative Commons Attribution 4.0 International License. Read Full License

Version of Record: A version of this preprint was published at Archives of Gynecology and Obstetrics on January 17th, 2022. See the published version at https://doi.org/10.1007/s00404-022-06396-5. 


\section{Abstract}

Introduction

Early endometrial cancer is primarily treated surgically via hysterectomy, adenectomy and, depending on tumor stage and subtype, lymphadenectomy. Systematic lymph node dissection is known to cause surgical complications. The aim of the present study was to investigate morbidity and mortality rates associated with lymphadenectomy in patients with endometrial cancer who underwent surgery in a routine clinical setting.

\section{Methods}

We collected data from 232 patients who were operated for endometrial carcinoma between 2006 and 2018 at the University of Luebeck, Germany. Surgical complications were viewed in relation to surgical risk factors. Additionally, a questionnaire concerning long-term lymphatic complications and survival was completed.

Survival was compared between patients who underwent lymphadenectomy (group I) and those who did not (group II).

Results

Patients in group I needed revision surgery significantly more often due to postoperative complications (such as lymphoceles) compared to those in group II $(p=0.01)$. The results indicate more serious complications in patients who underwent a systematic lymphadenectomy and in those with lymph node metastases.

$15 \%$ of patients who underwent a systematic lymphadenectomy had lymph node metastases. Recurrences occurred in $12.5 \%$ of cases and were significantly more frequent in patients who had undergone a lymphadenectomy, even if the lymph nodes were negative $(p=0.02)$. A comparison of survival data during the follow-up period revealed no significant difference.

The study highlighted the need for a better preoperative risk stratification and the avoidance of lymphadenectomy for surgical staging alone.

\section{Introduction}

The incidence of endometrial cancer increased by 2-5\% in the US from 1998 to 2013 [1,2]. Therefore, reducing complication rates after endometrial cancer surgery would be very desirable. Endometrial cancer, the most common gynecological carcinoma, is associated with approximately 11,300 new diagnoses per year in Germany [2,3]. 
Especially due to the increasing incidence of the metabolic syndrome, which is one of the prime risk factors for developing endometrial carcinoma, one may expect an ongoing increase in the occurrence of this cancer during the next decades. Additionally, the prevalence of obesity is on the rise and obesity is known to exert a harmful effect on surgical outcomes.

Gentle treatment has become a part of many oncologic therapies, such as those for breast cancer. The frequency of systematic lymphadenectomy has been reduced. Patients with clinically negative lymph nodes did not have different recurrence-free or overall survival intervals during a 25-year follow-up, regardless of whether a systematic lymphadenectomy was performed [4]. In fact, a systematic axillary lymph node dissection was not needed in specific patients with positive lymph nodes. [5] Thus, adverse outcomes directly caused by lymph node dissection, such as lymphedema, were reduced from $15.3 \%$ after axillary lymph node dissection to $3.3 \%$ after sentinel node biopsy [4]. Ongoing research has been focused on reducing the extent of treatment in endometrial cancer, despite clear differences between the lymphatic drainage of the uterus and that of the mammary glands [6].

Notwithstanding the value of lymphadenectomy as a surgical staging procedure in endometrial cancer, its therapeutic effect remains controversial [7]. On the one hand, lymph node metastases are a common occurrence in endometrial cancer. On the other hand, systematic lymphadenectomy may cause intra- and postoperative complications, which might impair the patients' quality of life postoperatively. According to Leitao et al., $40.9 \%$ of patients receiving a systematic lymphadenectomy for endometrial cancer experience long-term lymphatic complications such as lymphocele and lymphedema; these complications are significantly less common in patients without systematic lymph node dissection. Patients with postoperative lymphedema reported a significantly poorer quality of life compared to those without lymphedema [8]. Systematic lymphadenectomy is associated with relatively high complication rates compared to hysterectomy with adenectomy alone, which is performed in cases of low-risk endometrial carcinoma. The most common complications of systematic lymphadenectomy are intraoperative bleeding, injury to neighboring organs, postoperative lymph cysts (up to $34.5 \%$ of the cases), and lower-limb edema $[9,10]$. Since more than a half of the patients undergoing a lymphadenectomy (LD) do not have lymph node metastases, the procedure may not improve survival [11-13]. The technique of sentinel node biopsy has been refined over the last few years [14-16]. The sentinel node technique has been validated for use in endometrial cancer, but was not incorporated in the standard of care during the period of the present study [17].

In stage I endometrial carcinoma, systematic lymphadenectomy improves neither recurrence-free survival nor overall survival [18]. Endometrial cancer may be treated by laparoscopy or laparotomy [19]. Open surgery is known to cause higher complication rates than laparoscopic procedures [20].

Hitherto, we still do not know whether lymphadenectomy performed in high-risk patients does improve survival or only serves as a useful staging procedure. While the discussion concerning its survival advantage is still in progress, long-term complication rates have been a neglected problem. 
The aim of the present study was to obtain evidence about relevant surgical risk factors and postoperative morbidity. A further aim was to determine the impact of systematic lymphadenectomy on surgical and oncological outcomes.

\section{Patients And Methods}

A retrospective analysis was performed at the department of obstetrics and gynecology, University of Luebeck, Germany. The medical files of all patients who underwent surgery for endometrial carcinoma from 2006 to 2018 were retrieved from the electronic information system of the hospital. Exclusion criteria were no surgical treatment, incomplete resection (R1), and the absence of patient consent. The study was performed in compliance with the Helsinki declaration and approved by the ethics committee of the University of Luebeck (19-082A). Three hundred patients were recruited and 232 met the inclusion criteria. Patients were divided into two groups: group I consisted of those who had undergone a systematic lymphadenectomy ( $n=133)$, and group II comprised patients with no systematic lymphadenectomy $(n=99)$.

A subgroup analysis was performed for comparison of clinical data. Patients who had undergone a systematic lymphadenectomy but had negative lymph nodes $(n=113)$ and patients without lymphadenectomy $(n=99)$ were compared. Additionally, surgical complications and risk factors such as BMI, diabetes mellitus, and nicotine abuse were analyzed.

Medical history, details of surgery, histology, tumor stage, and postoperative data were reviewed. The questionnaire was sent first to collect postoperative data. To assess treatment-related morbidity, the questionnaire addressed long-term surgical complications including lymphedema, symptomatic lymphocysts, pain related to surgery, and disease recurrence. Lymphocysts, wound healing disorders and lymphedema were defined as lymphatic complications. Patient data were analyzed in regard of independent risk factors such as nicotine abuse, previous surgery in the abdomen, the ECOG (Eastern Cooperative Oncology Group) performance status, parity, and diabetes mellitus. Surgical complications were analyzed separately for patients with a BMI higher than $30 \mathrm{~kg} / \mathrm{m}^{2}$, and for those with positive versus negative lymph nodes after systematic lymph node dissection. Moreover, the overall (OS) and recurrencefree survival (progression-free survival, PFS) rates were evaluated.

The FIGO staging system was used to categorize disease. Pathologists make a distinction between type I, type II, and undifferentiated endometrial carcinoma. A systematic pelvic and para-aortic lymphadenectomy was performed in patients with intermediate- or high-risk endometrial cancer in accordance with the current German guidelines [17].

The choice between the laparoscopic and the open approach depended on the patient's individual situation. The Clavien-Dindo classification was used to compare surgical complication rates [21]. Shortterm postoperative complications were those that occurred up to one month after surgery. Grade I and II complications were considered mild, while Grade III-V complications were rated severe. The questionnaire 
was sent to the patients a second time in order to assess long-term complications. Patients without sufficient data records were excluded from the analysis.

Statistical analyses were performed using the free Python software, version 3.7, including the packages Pandas, Lifelines, SciPy and NumPy [22].

To compare absolute and relative frequencies of clinical parameters, we used a variety of statistical tests depending on the scaling and distribution of variables. Fisher's exact test was used for binary variables. The test yields the deviation of the result from the null hypothesis, and was proven valid even for small sample sizes. The Chi-square test was used for larger sample sizes with several categorical scaled variables. The Chi-squared test demonstrates any significant differences between observed frequencies and expected frequencies in a contingency table. Finally, the Mann-Whitney U-test was employed in some cases of ordinal scaled variables. It is a nonparametric test to compare differences between two probabilities. Survival data were analyzed using Kaplan-Meier-curves; confidence intervals indicate the degree of uncertainty.

\section{Results}

Median age was similar in patients with (65.4 \pm 11.5 years) and without lymphadenectomy $(65.5 \pm 13.5$ years). The patients' average BMI was $30.8 \pm 8.6 \mathrm{~kg} / \mathrm{m}^{2}$, which indicated an obese cohort. Overall, $42.9 \%$ of patients had a BMI higher than $30 \mathrm{~kg} / \mathrm{m}^{2}$. Patients without lymphadenectomy were significantly more obese than those who had undergone systematic lymphadenectomy $(p<0.01)$. Previous surgeries have been mentioned as an independent risk factor for surgical complications. Approximately one half of the patients had undergone abdominal surgery prior to being diagnosed with endometrial cancer. The two groups did not differ significantly in regard of previous surgeries $(p=0.23)$. The majority of patients was postmenopausal (83 \%). On average, the patients had born 1.7 children; parity did not differ between groups. Tumor stages (according to the FIGO classification) did not differ significantly, except for those with FIGO III-IV disease. Of patients in the latter group, those who underwent lymphadenectomy were significantly more numerous than those who did not. Baseline characteristics are shown in Table 1, and the subgroup analysis in Table 2.

With regard to surgical technique, a conversion from laparoscopy to laparotomy was needed in 16 cases. Laparotomy was used in 82 patients and the laparoscopic approach in 150 patients. When a lymphadenectomy was performed, an average of 11.5 lymph nodes were removed. An endometrioid endometrial cancer was diagnosed in 219 patients, and a serous or clear cell histology in 13 patients. The mean duration of surgery was significantly longer when a lymphadenectomy was performed $(p<0.001)$; these patients also needed repeat surgery significantly more often because of postoperative complications such as lymphoceles $(p<0.001$; Table 1). Performance status (ECOG) did not differ significantly between groups. Lymphatic complications were significantly more common in group I than in group II $(p=0.01)$. Furthermore, patients undergoing a lymphadenectomy had a significantly longer hospital stay than patients who did not $(p<0.001)$, and discharged significantly more fluid through the 
abdominal drain $(p<0.001)$. Patients receiving a systematic lymphadenectomy lost significantly more blood intraoperatively $(p=0.002$, Table 1$)$, and thus experienced significantly greater postoperative morbidity than those who had no lymphadenectomy.

Table 2 shows clinical characteristics of patients with a negative lymph node status after lymphadenectomy compared to patients without lymphadenectomy. Patients with negative lymph nodes after surgical staging had recurrent disease significantly more often than those without lymphadenectomy ( $p=0.02$, Table 2$)$. Average complication rates did not differ significantly.

Surgical complications were categorized according to the Clavien-Dindo classification. No patient died due to surgery (Clavien-Dindo grade $\mathrm{V}$ ). Despite the representative nature of the study sample, severe complications were rarely seen in the present investigation. The majority of patients had no or mild (grade I or II) complications. Surgical complications were analyzed with reference to various risk factors, as shown in Table 3.

Given the rarity of severe complications, $p$-values were not computed in the present analysis. A tendency towards more serious complications was noted in patients undergoing systematic lymphadenectomy and those with lymph node metastases. BMI or the presence of diabetes mellitus did not appear to have influenced the frequency of surgical complications (Table 3). Approximately $15 \%$ of patients who received a lymph node dissection were diagnosed with lymph node metastases; $35 \%$ of these experienced severe surgical complications while $17.3 \%$ of all patients who underwent a systematic lymphadenectomy experienced severe surgical complications.

Based on the questionnaire, the mean duration of follow-up was 59.5 months. During this time, $50 \%$ of patients were lost to follow-up. Thirty-one of these patients (13.4\%) died during the follow-up period. The median OS and PFS of the entire group was 50 months and 36 months, respectively.

Patients with lymphadenectomy (LD) had a similar median PFS (29 months, 95\% Cl 0.99-0.25) as patients without lymphadenectomy ( 47 months, $95 \% \mathrm{Cl} 0.99-0.61 ; p=0.07$ ) (Figure 2).

Overall survival did not differ significantly between patients with negative lymph nodes and those without lymph node staging. Median OS was 48.5 months in patients with lymphadenectomy $(95 \% \mathrm{Cl} 0.99-$ 0.26 ) versus 50 months in those without lymphadenectomy ( $95 \% \mathrm{Cl} 0.99-0.72, p=0.07$; Figure 3$)$. As shown by the $95 \%$ confidence intervals in Figures 2 and 3, survival rates were associated with relatively high uncertainty. When comparing two groups, an overlap of confidence intervals indicates a statistically non-significant result. Consequently, the calculated differences between the two curves did not differ significantly.

\section{Discussion}

We evaluated surgical complications, long-term morbidity (lymphatic complications and recurrences), and mortality in patients with endometrial cancer who underwent surgery with and without 
lymphadenectomy. According to the published literature, a systematic lymphadenectomy does not improve the prognosis of disease but may exert a positive effect on postoperative morbidity. We registered predominantly minor surgical complications and encountered no mortality as a result of surgery. Nevertheless, the high overall survival rate in patients with endometrial cancer $(85-90 \%$ in the first five years) calls for treatment with minimized risks and complications $[17,23]$.

One of the foremost controversies in the treatment of endometrial cancer is lymphadenectomy. Two randomized phase-III trials yielded no survival benefit in patients with early endometrial carcinoma who underwent lymph node dissection $[13,18]$. Nevertheless, systematic lymphadenectomy is an important tool for surgical staging.

The impact of lymph node dissection on surgical complication rates and long-term morbidity has been neglected for a long time. We performed a retrospective evaluation of potential risk factors for surgical complications, such as ECOG, blood loss, BMI, nicotine abuse, and diabetes mellitus, with regard to lymph node dissection in endometrial cancer.

The fact that lymphadenectomy causes significantly more surgical complications than a hysterectomy in combination with adenectomy for endometrial cancer was reaffirmed in the present study. Guidelines in Germany recommend the removal of at least 30 lymph nodes (pelvic and para-aortic) when performing a systematic lymphadenectomy. Although the average number of resected lymph nodes in our patients was relatively small (11.5 pelvic lymph nodes), we registered a significant number of severe long-term lymphatic complications. Patients who undergo a lymphadenectomy are at significantly higher risk of needing revision surgery than those without lymphadenectomy.

The present study revealed that patients with systematic lymphadenectomy do not achieve better overall survival rates than those who do not undergo lymphadenectomy. One of the reasons may have been the small number of resected lymph nodes. Only $15 \%$ of our patients who underwent a systematic lymphadenectomy had positive lymph nodes (lymph node metastases). This is in line with other studies, in which a mere 15-20\% of patients had positive lymph nodes after lymphadenectomy [27]. Muallem et al. reported positive lymph node metastases in 11.3-16.1\% of patients with endometrial cancer in FIGO stages I or II [28]. Our data concerning the prevalence of positive lymph nodes after lymphadenectomy in endometrial cancer are in line with those reported by Odagiri et al. in 2014 (15.8\%), and Candido et al. in $2019[11,29]$. The latter authors registered no benefit in regard of disease-free or overall survival in patients with intermediate-risk endometrial carcinoma who had undergone a systematic lymphadenectomy.

Xu et al. evaluated, retrospectively, the effect of lymphadenectomy on survival rates in patients with (type I and type II) endometrial cancer. The authors aimed to determine the number of lymph nodes to be resected in order to achieve an overall survival benefit, and found no threshold for endometrioid endometrial carcinoma [30]. This is in line with our data, which indicated that systematic lymphadenectomy does not improve overall survival rates. Further studies have also shown that lymph node dissection does neither improve overall survival nor progression-free survival in patients with 
endometrial cancer $[13,31,32]$. Benedetti et al. observed an overall survival rate of $85.9 \%$ in patients who underwent a lymphadenectomy versus $81.7 \%$ in patients without lymphadenectomy. In line with these data, we registered an overall survival rate of $87 \%$ in both groups. In contrast, Saotome et al. recently reported significantly better overall survival rates in patients who had undergone systematic lymph node dissection. However, the above mentioned study differed markedly from others in respect of group sizes (only $27 \%$ of all patients had no lymphadenectomy), age, and FIGO stages [33].

The limitations of the present study are its retrospective nature and the relatively small sample size; a half of the patients were lost in follow-up. However, the results serve as a contribution to the ongoing discussion about treatment-related morbidity and mortality in patients with endometrial cancer.

We conclude that, in patients with early endometrioid endometrial cancer and clinically unsuspicious lymph nodes, a systematic lymph node dissection causes clinically relevant short- and long-term complications. Furthermore, a lymphadenectomy may have no impact on recurrence and overall survival rates. The data highlight the need for better preoperative risk stratification and surgical procedures such as sentinel node biopsy. The usefulness of radical lymphadenectomy may possibly be limited to surgical staging.

\section{References}

[1] Lortet-Tieulent J, Ferlay J, Bray F, u. a. International Patterns and Trends in Endometrial Cancer Incidence, 1978-2013. JNCl: Journal of the National Cancer Institute 2018; 110: 354-361

[2] Molekulare Gynäkologie und Geburtshilfe für die Praxis. Stuttgart: Georg Thieme Verlag, 2016

[3] Gitas G, Proppe L, Alkatout I, u. a. Accuracy of frozen section at early clinical stage of endometrioid endometrial cancer: a retrospective analysis in Germany. Arch Gynecol Obstet 2019; 300: 169-174

[4] Noguchi M, Inokuchi M, Noguchi M, u. a. Axillary surgery for breast cancer: past, present, and future. Breast Cancer 2020; Im Internet: http://link.springer.com/10.1007/s12282-020-01120-0

[5] Giuliano AE, Ballman KV, McCall L, u. a. Effect of Axillary Dissection vs No Axillary Dissection on 10Year Overall Survival Among Women With Invasive Breast Cancer and Sentinel Node Metastasis: The ACOSOG Z0011 (Alliance) Randomized Clinical Trial. JAMA 2017; 318: 918

[6] Freytag D, Pape J, Dhanawat J, u. a. Challenges Posed by Embryonic and Anatomical Factors in Systematic Lymphadenectomy for Endometrial Cancer. JCM 2020; 9: 4107

[7] Bogani G, Dowdy SC, Cliby WA, u. a. Role of pelvic and para-aortic lymphadenectomy in endometrial cancer: Current evidence: Lymphadenectomy in endometrial cancer. J Obstet Gynaecol Res 2014; 40: $301-311$ 
[8] Leitao MM, Zhou QC, Gomez-Hidalgo NR, u. a. Patient-reported outcomes after surgery for endometrial carcinoma: Prevalence of lower-extremity lymphedema after sentinel lymph node mapping versus lymphadenectomy. Gynecologic Oncology 2020; 156: 147-153

[9] Achouri A, Huchon C, Bats AS, u. a. Complications of lymphadenectomy for gynecologic cancer. European Journal of Surgical Oncology (EJSO) 2013; 39: 81-86

[10] Abu-Rustum NR, Alektiar K, lasonos A, u. a. The incidence of symptomatic lower-extremity lymphedema following treatment of uterine corpus malignancies: A 12-year experience at Memorial Sloan-Kettering Cancer Center. Gynecologic Oncology 2006; 103: 714-718

[11] Candido EC, Rangel Neto OF, Toledo MCS, Torres JCC, Cairo AAA, Braganca JF, Teixeira JC. Systematic lymphadenectomy for intermediate risk endometrial carcinoma treatment does not improve the oncological outcome. Eur J Obstet Gynecol Reprod Biol X 2019; 18

[12] Volpi, L.; Sozzi, G.; Capozzi, V.A.; Ricco, M.; Merisio, C.; Di Serio, M.; Chiantera, V.;Berretta, R. Long term complications following pelvic and para-aortic lymphadenectomy for endometrial cancer, incidence and potential risk factors: a single institution experience. Int J Gynecol Cancer $312 \mathrm{n}$. Chr.;

[13] Panici PB, Basile S, Maneschi F, u. a. Systematic Pelvic Lymphadenectomy vs No Lymphadenectomy in Early-Stage Endometrial Carcinoma: Randomized Clinical Trial. JNCl Journal of the National Cancer Institute 2008; 100: 1707-1716

[14] Capozzi VA, Sozzi G, Uccella S, u. a. Novel preoperative predictive score to evaluate lymphovascular space involvement in endometrial cancer: an aid to the sentinel lymph node algorithm. Int $\mathrm{J}$ Gynecol Cancer 2020; ijgc-2019-001016

[15] Mueller JJ, Pedra Nobre S, Braxton K, Alektiar KM, Leitao MM Jr, Aghajanian C, Ellenson LH, AbuRustum NR4. Incidence of pelvic lymph node metastasis using modern FIGO staging and sentinel lymph node mapping with ultrastaging in surgically staged patients with endometrioid and serous endometrial carcinoma. Gynecol Oncol 2020;

[16] Accorsi GS; Paiva LL; Schmidt R; Vieira M; Reis, R; Andrade C. Sentinel Lymph Node Mapping vs Systematic Lypohadenectomy for Endometrial Cancer: Surgical Morbidity and Lymphatic Complications. JMIG 2019;

[17] Emons G, Steiner E. S3-Leitlinie Diagnostik, Therapie und Nachsorge der Patientinnen mit Endometriumkarzinom. Gynäkologe 2018; 51: 996-999

[18] Efficacy of systematic pelvic lymphadenectomy in endometrial cancer (MRC ASTEC trial): a randomised study. The Lancet 2009; 373: 125-136

[19] Papadia A, Garbade A, Gasparri ML, U. a. Minimally invasive surgery does not impair overall survival in stage IIIC endometrial cancer patients. Arch Gynecol Obstet 2020; 301: 585-590 
[20] Walker JL, Piedmonte MR, Spirtos NM, U. a. Laparoscopy compared with laparotomy for comprehensive surgical staging of uterine cancer: Gynecologic Oncology Group Study LAP2. J Clin Oncol 2009; 27: 5331-5336

[21] Clavien PA, Barkun J, de Oliveira ML, u. a. The Clavien-Dindo Classification of Surgical Complications: Five-Year Experience. Annals of Surgery 2009; 250: 187-196

[22] 28.27. Anaconda Software Distribution. Computer software. Vers. 2-2.4.0. Anaconda, Nov. 2016. Web. <https://anaconda.com>.

[23] de Boer SM, Powell ME, Mileshkin L, u. a. Adjuvant chemoradiotherapy versus radiotherapy alone for women with high-risk endometrial cancer (PORTEC-3): final results of an international, open-label, multicentre, randomised, phase 3 trial. The Lancet Oncology 2018; 19: 295-309

[24] Carter J, Huang HQ, Armer J, u. a. GOG 244 - The Lymphedema and Gynecologic cancer (LeG) study: The impact of lower-extremity lymphedema on quality of life, psychological adjustment, physical disability, and function. Gynecologic Oncology 2020; S0090825820340452

[25] Togami S, Kawamura T, Fukuda M, u. a. Risk factors for lymphatic complications following lymphadenectomy in patients with cervical cancer. Japanese Journal of Clinical Oncology 2018; 48: $1036-1040$

[26] Świrska J, Czuczwar P, Zwolak A, u. a. Perioperative complications of gynecologic surgery in diabetic patients. Ginekol Pol 2016; 87: 194-199

[27] Urunsak IF, Khatib G, Vardar MA, u. a. Challenges on the morbidly obese endometrial cancer surgery: Laparotomy or laparoscopy, lymphadenectomy or no lymphadenectomy? Ginekologia Polska 2020; 91: 7

[28] Muallem MZ, Sehouli J, Almuheimid J, u. a. Risk Factors of Lymph Nodes Metastases by Endometrial Cancer: A Retrospective One-center Study. ANTICANCER RESEARCH 2016; 7

[29] Odagiri T, Watari H, Kato T, u. a. Distribution of Lymph Node Metastasis Sites in Endometrial Cancer Undergoing Systematic Pelvic and Para-Aortic Lymphadenectomy: A Proposal of Optimal Lymphadenectomy for Future Clinical Trials. Ann Surg Oncol 2014; 21: 2755-2761

[30] Xu J, Chen C, Xiong J, u. a. Differential Impact of Systemic Lymphadenectomy Upon the Survival of Patients with Type I vs Type II Endometrial Cancer: A Retrospective Observational Cohort Study. CMAR 2020; Volume 12: 12269-12276

[31] Liu C, Zhao J, Liu S, u. a. Effect of Pelvic Lymphadenectomy on Survival in Patients with Low-Risk Early-Stage Endometrial Cancer Diagnosed Intraoperatively Using Frozen Tissue Sections: A Retrospective Analysis. CMAR 2020; Volume 12: 10715-10723 
[32] Ignatov A, Papathemelis T, Ivros S, u. a. Comparison of survival of patients with endometrial cancer undergoing sentinel node biopsy alone or systematic lymphadenectomy. Arch Gynecol Obstet 2020; 302: 995-1000

[33] Saotome K, Yamagami W, Machida H, u. a. Impact of lymphadenectomy on the treatment of endometrial cancer using data from the JSOG cancer registry. Obstet Gynecol Sci 2020; Im Internet: http://ogscience.org/journal/view.php?doi=10.5468/ogs.20186

[34] Eoh K-J, Nam E-J, Kim S-W, u. a. Nationwide Comparison of Surgical and Oncologic Outcomes in Endometrial Cancer Patients Undergoing Robotic, Laparoscopic, and Open Surgery: A Population-Based Cohort Study. Cancer Res Treat 2020; Im Internet: http://www.e-crt.org/journal/view.php? doi $=10.4143 /$ crt.2020.802

[35] Limbachiya D. Surgicopathological outcomes and survival in carcinoma body uterus: A retrospective analysis of cases managed by laparoscopic staging surgery in Indian women. Gynecol Minim Invasive Ther 2020; 9: 139

\section{Tables}

Table 1. Baseline characteristics and clinical data of patients with and without lymphadenectomy. 


\begin{tabular}{|c|c|c|c|c|}
\hline & $\begin{array}{l}\text { Patients with } \\
\text { systematic } \\
\text { lymphadenectomy } \\
(n=133)\end{array}$ & $\begin{array}{l}\text { Patients without } \\
\text { systematic } \\
\text { lymphadenectomy } \\
(n=99)\end{array}$ & $\begin{array}{l}\text { Total } \\
(n=232)\end{array}$ & $\begin{array}{l}p- \\
\text { value }\end{array}$ \\
\hline Age (average, years) & $65.4 \pm 11.5$ & $65.5 \pm 13.5$ & $\begin{array}{l}65.4 \pm \\
12.3\end{array}$ & n.s. \\
\hline FIGO I-II & $100(43.1 \%)$ & $93(40.1 \%)$ & $\begin{array}{l}193 \\
(83.2 \%)\end{array}$ & n.s. \\
\hline FIGO III-IV & $33(14.2 \%)$ & $6(2.6 \%)$ & $\begin{array}{l}39(16.8 \\
\%)\end{array}$ & 0.001 \\
\hline BMI (average, $\mathrm{kg} / \mathrm{m}^{2}$ ) & $29.4 \pm 7.9$ & $32.8 \pm 9.3$ & $\begin{array}{l}30.8 \pm \\
8.6\end{array}$ & $\begin{array}{l}< \\
0.01\end{array}$ \\
\hline $\begin{array}{l}\text { Revision surgery } \\
\text { needed }\end{array}$ & $31(13.4 \%)$ & $8(3.4 \%)$ & $\begin{array}{l}39(16.8 \\
\%)\end{array}$ & $\begin{array}{l}< \\
0.001\end{array}$ \\
\hline $\begin{array}{l}\text { Average duration of } \\
\text { surgery (minutes) }\end{array}$ & $227.2 \pm 97.4$ & $132.8 \pm 60.9$ & $\begin{array}{l}187.3 \pm \\
96\end{array}$ & <. 001 \\
\hline $\begin{array}{l}\text { Average duration of } \\
\text { hospitalization }\end{array}$ & $10.0 \pm 7.4$ & $6.0 \pm 6.0$ & $8.3 \pm 7.2$ & $\begin{array}{l}< \\
0.001\end{array}$ \\
\hline Recurrence & $22(9.5 \%)$ & $7(3 \%)$ & $\begin{array}{l}29 \\
\%)\end{array}$ & 0.04 \\
\hline $\begin{array}{l}\text { Lymphatic } \\
\text { complication }\end{array}$ & $19(8.2 \%)$ & $2(0.9 \%)$ & $21(9 \%)$ & $\begin{array}{l}< \\
0.001\end{array}$ \\
\hline $\begin{array}{l}\text { Surgical drain output } \\
\text { (ml) }\end{array}$ & $2439.3 \pm 3212.0$ & $247.6 \pm 269.2$ & $\begin{array}{l}1502.9 \pm \\
2664.6\end{array}$ & $\begin{array}{l}< \\
0.001\end{array}$ \\
\hline $\begin{array}{l}\text { Intraoperative blood } \\
\text { loss }(\mathrm{g} / \mathrm{dl})\end{array}$ & $1.9 \pm 1.3$ & $1.3 \pm 1.1$ & $1.6 \pm 1.3$ & 0.002 \\
\hline $\begin{array}{l}\text { Death during follow- } \\
\text { up (data from }\end{array}$ & $23 / 63(36.5 \%)$ & 8/41 (19.5 \%) & $\begin{array}{l}31 / 105 \\
(29.5 \%)\end{array}$ & n.s. \\
\hline
\end{tabular}

Table 2. Subgroup analysis of patients with lymphadenectomy but negative lymph nodes, and patients without lymphadenectomy. 


\begin{tabular}{|c|c|c|c|c|}
\hline & $\begin{array}{l}\text { Patients with } \\
\text { negative lymph } \\
\text { nodes }(n=113)\end{array}$ & $\begin{array}{l}\text { Patients without } \\
\text { systematic } \\
\text { lymphadenectomy }(n=99)\end{array}$ & $\begin{array}{l}\text { Total } \\
(n=212)\end{array}$ & $\begin{array}{l}p- \\
\text { value }\end{array}$ \\
\hline Age (average, years) & $65.7 \pm 11.3$ & $65.5 \pm 13.5$ & $\begin{array}{l}65.6 \pm \\
12.3\end{array}$ & n.s. \\
\hline FIGO I-II & $100(47.2 \%)$ & $93(43.9 \%)$ & $\begin{array}{l}193 \\
(91.0 \%)\end{array}$ & n.s. \\
\hline FIGO III-IV & $13(6.1 \%)$ & $6(2.8 \%)$ & $\begin{array}{l}19(9.0 \\
\%)\end{array}$ & n.s. \\
\hline BMI (average, $\mathrm{kg} / \mathrm{m}^{2}$ ) & $30.0 \pm 7.9$ & $32.8 \pm 9.3$ & $\begin{array}{l}31.3 \pm \\
8.7\end{array}$ & $\begin{array}{l}< \\
0.001\end{array}$ \\
\hline $\begin{array}{l}\text { Surgical complications* } \\
1-\| l^{\circ}\end{array}$ & $97(45.5 \%)$ & $89(41.8 \%)$ & $\begin{array}{l}186 \\
(87.3 \%)\end{array}$ & n.s. \\
\hline $\begin{array}{l}\text { Surgical complications* } \\
\text { III- IV॰ }\end{array}$ & $16(7.5 \%)$ & $9(4.2 \%)$ & $\begin{array}{l}25(11.7 \\
\%)\end{array}$ & n.s. \\
\hline Revision surgery & $24(11.3 \%)$ & $8(3.8 \%)$ & $\begin{array}{l}32(15 \\
\%)\end{array}$ & 0.01 \\
\hline $\begin{array}{l}\text { Average duration of } \\
\text { surgery (minutes) }\end{array}$ & $221.9 \pm 96.9$ & $132.8 \pm 60.9$ & $\begin{array}{l}180.9 \pm \\
93.4\end{array}$ & $\begin{array}{l}< \\
0.001\end{array}$ \\
\hline $\begin{array}{l}\text { Average duration of } \\
\text { hospitalization }\end{array}$ & $9.9 \pm 7.8$ & $6.0 \pm 6.0$ & $8.1 \pm 7.3$ & $\dot{0} 001$ \\
\hline Recurrence & $20(9.4 \%)$ & $7(3.3 \%)$ & $\begin{array}{l}27(12.7 \\
\%)\end{array}$ & 0.02 \\
\hline $\begin{array}{l}\text { Lymphatic } \\
\text { complications }\end{array}$ & $14(6.6 \%)$ & $2(0.9 \%)$ & $\begin{array}{l}16(7.5 \\
\%)\end{array}$ & 0.004 \\
\hline $\begin{array}{l}\text { Surgical drain output } \\
(\mathrm{ml})\end{array}$ & $2385.0 \pm 3337.0$ & $250.3 \pm 269.2$ & $\begin{array}{l}1389.6 \pm \\
2668.0\end{array}$ & $\begin{array}{l}< \\
0.001\end{array}$ \\
\hline $\begin{array}{l}\text { Intraoperative blood loss } \\
(\mathrm{g} / \mathrm{dl})\end{array}$ & $1.8 \pm 1.3$ & $1.3 \pm 1.1$ & $1.6 \pm 1.3$ & n.s. \\
\hline $\begin{array}{l}\text { Death during follow-up } \\
\text { (data from 95/213 } \\
\text { patients) }\end{array}$ & $18 / 52(18.9 \%)$ & $8 / 43(8.4 \%)$ & $\begin{array}{l}26 / 95 \\
(27.4 \%)\end{array}$ & n.s. \\
\hline
\end{tabular}


*according to the Clavien-Dindo classification.

Table 3. Surgical complications in relation to risk factors.

\begin{tabular}{|c|c|c|c|}
\hline Surgical risk factor & $\begin{array}{l}\text { Surgical complications } \\
\text { category I or II }(n=199)\end{array}$ & $\begin{array}{l}\text { Surgical } \\
\text { complications } \\
\text { category III }(n=23)\end{array}$ & $\begin{array}{l}\text { Surgical } \\
\text { complications } \\
\text { category IV }(n=9)\end{array}$ \\
\hline $\begin{array}{l}\text { Diabetes mellitus } \\
(n=42)\end{array}$ & $34(17.1 \%)$ & $5(21.7 \%)$ & 0 \\
\hline Nicotine abuse $(n=39)$ & $35(17.6 \%)$ & $3(13.0 \%)$ & $1(11.1 \%)$ \\
\hline $\begin{array}{l}\mathrm{BMI} \geq 30 \mathrm{~kg} / \mathrm{m}^{2} \\
(n=100)\end{array}$ & $89(44.7 \%)$ & $7(30.4 \%)$ & $3(33.3 \%)$ \\
\hline $\begin{array}{l}\text { Systematic } \\
\text { lymphadenectomy } \\
(n=133)\end{array}$ & $110(55.3 \%)$ & $17(73.9 \%)$ & $6(67.7 \%)$ \\
\hline $\begin{array}{l}\text { No lymphadenectomy } \\
(n=99)\end{array}$ & $89(44.7 \%)$ & $9(39.1)$ & 0 \\
\hline $\begin{array}{l}\text { Previously operated } \\
\text { (no. of patients) } \\
(n=113)\end{array}$ & $97(48.7 \%)$ & $12(52.2 \%)$ & $4(44.4 \%)$ \\
\hline Laparotomy ( $n=82$ ) & $61(30.6 \%)$ & $14(60.9 \%)$ & $6(66.7 \%)$ \\
\hline Laparoscopy $(n=150)$ & $128(64.3 \%)$ & $10(43.5 \%)$ & $5(55.6 \%)$ \\
\hline
\end{tabular}

\section{Figures}




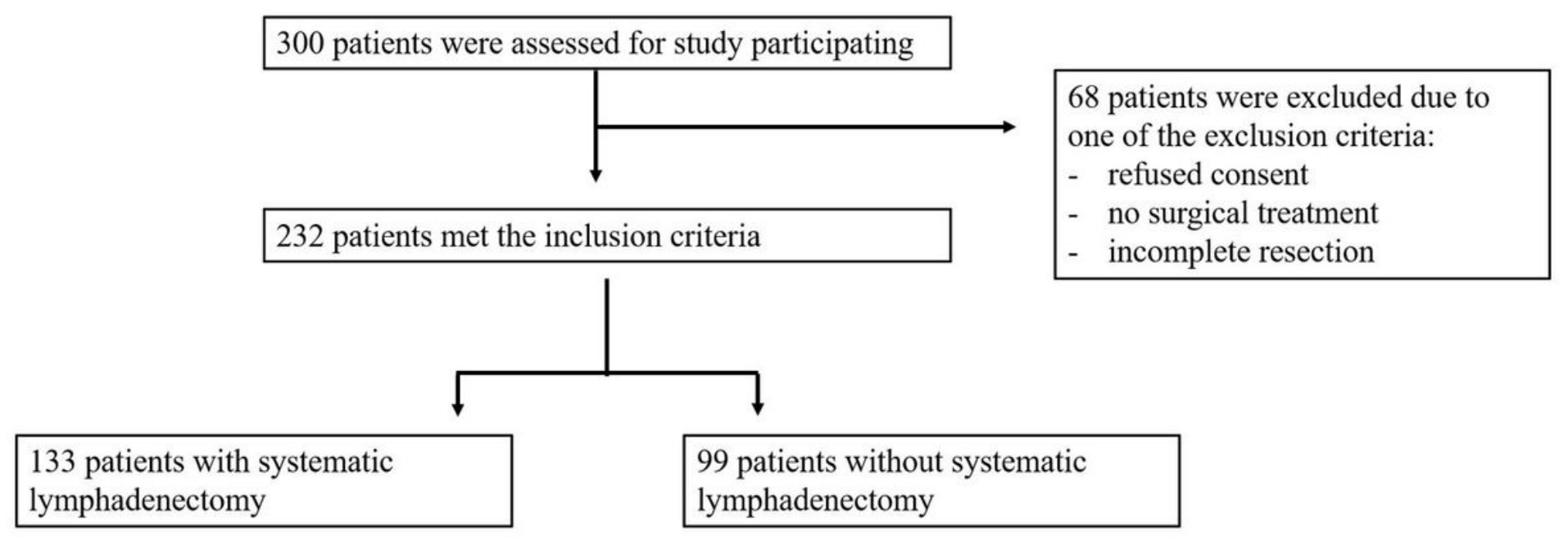

Figure 1

Consort diagram.

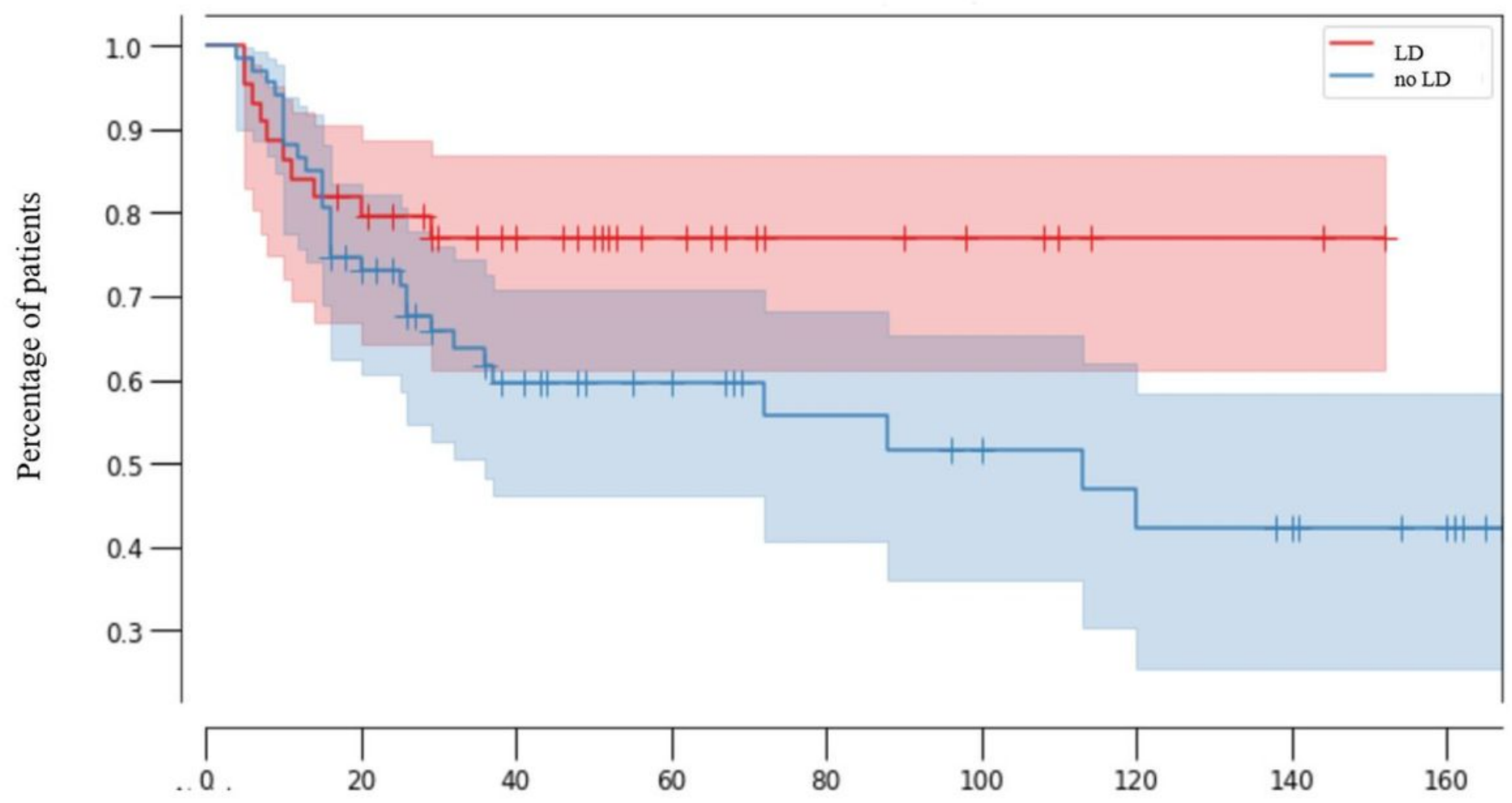

Disease-free survival in months

\section{Figure 2}

Kaplan-Meier analysis of progression-free survival in patients without lymphadenectomy (no LD, red line, $\mathrm{n}=44, \mathrm{Cl} 0.99-0.61)$ and with lymphadenectomy (LD, blue line, $\mathrm{n}=67,95 \% \mathrm{Cl} 0.99-0.25, \mathrm{p}=0.07)$ ). 


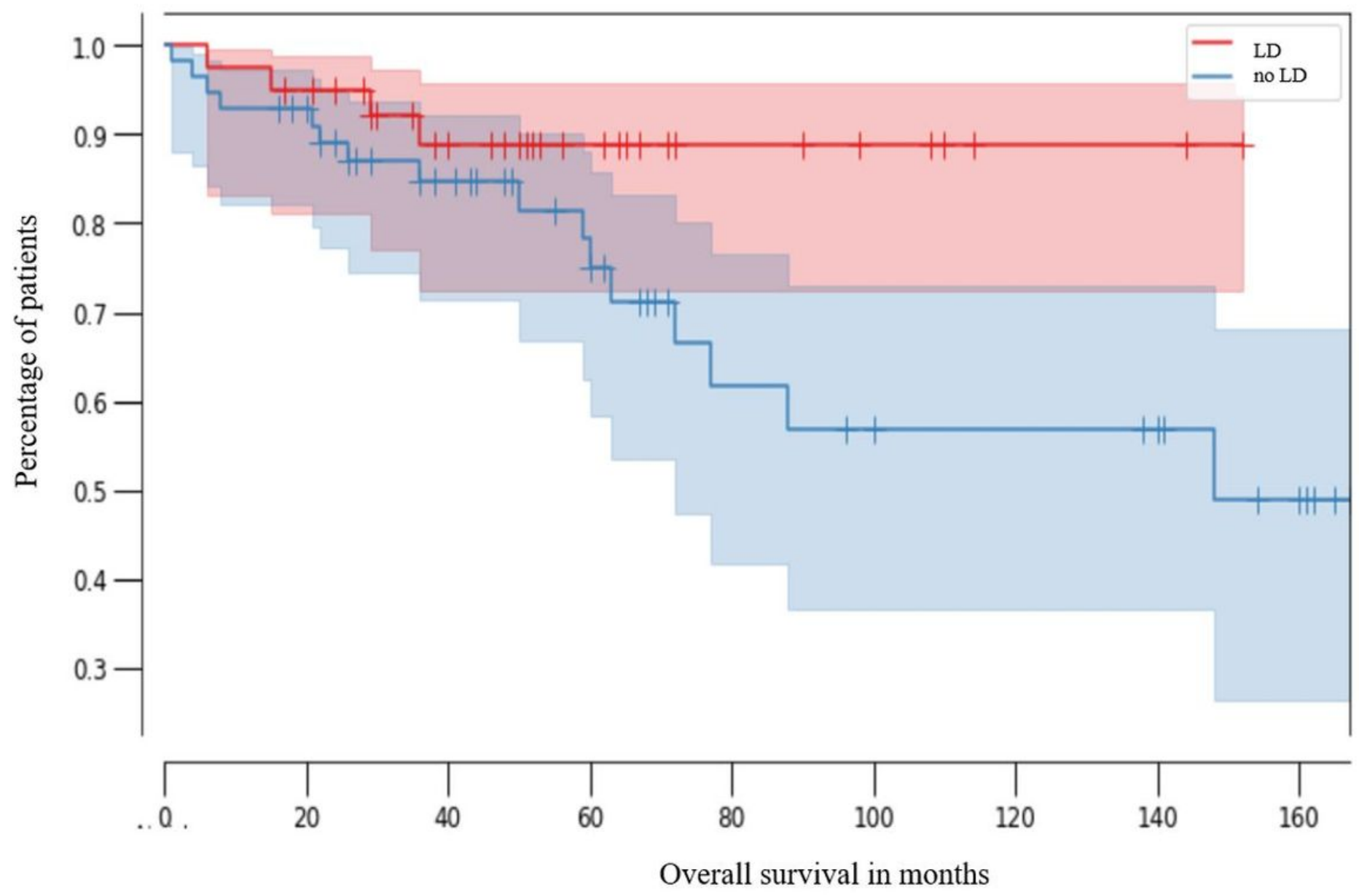

Figure 3

Kaplan-Meier analysis of overall survival in patients without lymphadenectomy (no LD, red line, $n=39$, median 50 months, $\mathrm{Cl}$ 0.99-0.72) and with lymphadenectomy (LD, blue line, $\mathrm{n}=56$, median 48.5 months, $\mathrm{Cl} 0.99-0.26)(p=0.07)$. 